\title{
Is it possible to develop a new measurement tool to assess the functional status in patients with rheumatoid arthritis?
}

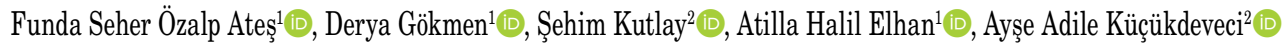 \\ ${ }^{1}$ Department of Biostatistics, Ankara University Faculty of Medicine, Ankara, Turkey \\ ${ }^{2}$ Department of Physical Medicine and Rehabilitation, Ankara University Faculty of Medicine, Ankara, Turkey
}

Received: June 20, 2020 Accepted: September 03, 2020 Published online: May 25, 2021

\begin{abstract}
Objectives: This study aims to develop measurement tools for assessing patients' functional status with rheumatoid arthritis (RA) in terms of upper and lower extremity function and to evaluate the tools' construct validities with classical and modern psychometric approaches.

Patients and methods: Between April 2010 and April 2012, a total of 300 patients with RA (77 males, 223 females; mean age: $52.3 \pm 11.5$ years; range, 18 to 82 years) who answered items from a range of widely used instruments were included. After examining initial dimensionality with exploratory factor analysis (EFA), confirmatory factor analysis (CFA), and Rasch analysis were used to evaluate the tools' construct validities. The data-model fit was evaluated with goodness-of-fit (GoF) statistics in CFA, while the tools were examined in terms of item and person fit, unidimensionality and differential item functioning (DIF) from the perspective of Rasch analysis.

Results: According to EFA, two dimensions were identified and named as "self-care-mobility-household activities related to lower extremity" and "self-care-mobility-household activities related to upper extremity" taking into account the factor loadings and the clinical classifications. While the clinical classification was tested with CFA, all items were loaded on their pre-defined dimensions with the factor loadings of $\geq 0.40$ and GoF statistics were within the acceptable ranges. When the "self-care-mobility-household activities related to upper extremity" and "self-care-mobility-household activities related to lower extremity" tools were evaluated via the Rasch analysis, both tools were found to fit the Rasch model expectations, with a mean item fit statistics of -0.528 logit (standard deviation [SD]: 1.365) and -0.213 (SD: 1.168; mean person fit statistics of -0.412 logit (SD: 1.160) and -0.303 logit (SD: 0.859), respectively.

Conclusion: For the evaluation of a scale's construct validity, it is recommended to use the Rasch analysis in tandem with factor analytic methods, as the Rasch analysis explores a scale's construct validity in terms of item and person fit, DIF and unidimensionality which is the only aspect of the factor analysis.
\end{abstract}

Keywords: Factor analysis, functional status, measurement tool, Rasch analysis, rheumatoid arthritis.

Rheumatoid arthritis (RA) is a chronic, systemic, inflammatory disease characterized by inflammatory polyarthritis. Outcome assessment in RA is fairly complex such as in other chronic diseases. The main areas of outcomes are joint damage, disease activity, and functional status. Each of these areas consisting of different domains can be assessed with various instruments. Functional status is an important outcome in patients with RA and refers to measures of functioning that capture the interaction between a person's health status and the ability to participate in activities. ${ }^{[1]}$ Functioning is usually evaluated with patient-reported questionnaires. ${ }^{[2]}$ A large number of outcome measures, such as the Health Assessment Questionnaire (HAQ), Arthritis Impact Measurement Scale-2 (AIMS2), and Short Form-36 (SF-36) are available to assess functioning in patients with RA. The HAQ is the most widely used patient reported outcome

Corresponding author: Funda Seher Özalp Ateş, PhD. Ankara Üniversitesi Tıp Fakültesi, Biyoistatistik Anabilim Dalı, 06590 Çankaya, Sihhiye, Ankara, Türkiye. e-mail: funda.ozalp@gmail.com 
measure to assess functional status in RA. The HAQ comprises 20 questions on activities involving both upper and lower extremities that are organized into eight categories (i.e., dressing, rising, eating, walking, hygiene, reach, grip, and usual activities). ${ }^{[3]}$

Although the classic clinical presentation of RA is a symmetric small joint synovitis of the hands and feet, involvement of the larger joints such as knees and elbows is common. In clinical practice, the evaluation of upper and lower limb function separately may be needed in some cases. Functional assessment instruments used in RA usually assess general functioning, without focusing on the upper or lower extremity activities. ${ }^{[4]}$

Factor analysis is a multivariate statistical analysis method which aims to find fewer meaningful and independent variables from a set of dependent variables that are related to each other. ${ }^{[5]}$ The aim of factor analysis in scale development is to show whether the items in the scale measure the actual structure investigated. Rasch analysis is a widely used method in the scale development process, which examines whether the current dataset complies with the measurement model developed by Georg Rasch ${ }^{[6]}$ and to what extent it meets the criteria required for a successful measurement.

In the present study, we aimed to develop measurement tools to assess functional status of patients with RA in terms of upper and lower extremity functions separately and to evaluate of the tools' construct validities with classical (factor analysis) and modern (Rasch analysis) psychometric approaches.

\section{PATIENTS AND METHODS}

This methodological study was conducted at Ankara University Faculty of Medicine and Ankara Numune Training and Research Hospital, Department of Physical Medicine and Rehabilitation between April 2010 and April 2012. In this study, data obtained from $300 \mathrm{RA}$ patients ( 77 males, 223 females; mean age: $52.3 \pm 11.5$ years; range, 18 to 82 years) within the scope of a previously conducted TÜBİTAK project were used (Disability Assessment with Computer Adaptive Test Method in Patients with Rheumatoid Arthritis. TÜBİTAK 1001 Research Projects, 109S342, 2010-2012). ${ }^{[7]}$ A written informed consent was obtained from each patient. The study protocol was approved by the Ethics Committee of the Faculty of Ankara University (Date/no: April 07, 2008/127-3559).
The study was conducted in accordance with the principles of the Declaration of Helsinki.

\section{Outcome measures}

In the previously conducted project, 300 patients with RA answered items from a range of widely used instruments: World Health Organization-Disability Assessment Schedule II (WHODAS-II) ${ }^{[8]}$ Nottingham Health Profile (NHP), ${ }^{[9]} \mathrm{HAQ},{ }^{[3]}$ and AIMS2. ${ }^{[10]}$ Validated Turkish versions of the scales were used. ${ }^{[11-14]}$ Among the all scales, 32 items specific to "self-caremobility-household activities" for only lower and for only upper extremities were selected for this study.

\section{Internal construct validity}

Within the scope of this study, the construct validities of the measurement tools were evaluated by both factor analytic methods and Rasch analysis.

\section{Factor analysis}

Factor analysis is a multivariate statistical analysis method which aims to find fewer meaningful and independent variables from a set of dependent variables that are related to each other. Factor analysis is examined according to the purpose of analysis as exploratory or confirmatory factor analysis (CFA). Exploratory factor analysis (EFA) is a statistical method used to determine the number of latent factors to be formed from the item set without any prior knowledge. ${ }^{[15]}$ In CFA, it is evaluated whether the items constitute the pre-defined dimensions in the light of prior knowledge.

As the first stage, the internal construct validity of the measurement tool was evaluated with EFA in the categorical data. The conventional factor analysis is not appropriate for use in the analysis of categorical data, since it is based on the principal component analysis and determines more dimensions than it actually has. Therefore, a robust weighted least squares method based on polychoric/tetrachoric correlations and the Geomin rotation method were used to analyze data. ${ }^{[15]}$ When more than one dimension was found in the EFA, the measurement tool(s) were created separately for these dimensions. While creating the measurement tools, the clinical classifications of the items were taken into consideration and obtained dimensions were named by considering these classifications. Items, that did not load to any dimension (factor loading in each dimension $<0.40$ ), were excluded from the study.

As the second stage, the internal construct validities of the measurement tools were evaluated 
with CFA in the categorical data. In this stage, it was investigated whether the factors obtained from clinical classification were able to explain the covariance structure of the items. Similar to EFA, items, that did not load to any dimension (factor loading in each dimension $<0.40$ ), were excluded from the study.

While evaluating the psychometric properties of the measurement tools found in EFA and CFA, goodness-of-fit (GoF) statistics were used. With the GoF statistics, it is decided whether the factors actually consist of these items. The most commonly used GoF statistics are the Goodness-of-Fit Index (GFI), the Adjusted Goodness of Fit Index (AGFI), the Comparative Fit Index (CFI), the Tucker-Lewis Index (TLI), the Root Mean Square Error of Approximation (RMSEA), Root Mean Square Residual (RMSR), and the Weighted Root Mean Residuals (WRMR). The values for the first four greater than 0.90/0.95 are considered acceptable/good fit. For the last three, values below $0.05 / 0.08$ are considered good/acceptable fit. ${ }^{[15]}$ The GoF statistics used in the study were CFI, TLI, and RMSEA.

A trial version of the MPlus 6.1 (Muthén \& Muthén, CA, USA $)^{[16]}$ was used for EFA and CFA.

\section{Rasch analysis}

The Rasch analysis is a widely used method in scale development process, which examines whether the current data set complies with the measurement model developed by Rasch ${ }^{[6]}$ and to what extent it meets the criteria required for a successful measurement. It assists the correct evaluation of the individuals by providing the transformation of the answers obtained with ordinal scale to the interval variable in case the Rasch model meets the expectations. ${ }^{[6,17]}$

Although RM was originally developed for dichotomous items, it has models that can be used for polytomous items. They are the partial credit model (PCM) and the rating scale model (RSM).

For Rasch analysis, the following standard protocol must be met. ${ }^{[15]}$

- Testing the internal consistency of the measurement tool for unidimensionality

- Examination of the compatibility of the items in the measurement tool with the model

- Testing whether the items provide invariance

- Testing whether the thresholds are ordered (For polytomous items)

- Testing of differential item functioning (DIF)
In the scope of this study, PCM was used for examination of measurement tools. At the end of this analysis, items that do not comply with the model, show DIF in terms of age, sex, and/or disease duration and disrupt the unidimensionality assumption were excluded from the measurement tools. The age variable was divided into four categories according to the quartiles ( $\leq 43,44-52$, $53-60, \geq 61$ years), while disease duration was divided into two categories ( $\leq 10,>10$ years), according to the median. The RUMM version 2020 program was used for the Rasch analysis. ${ }^{[18]}$

\section{RESULTS}

The mean disease duration was $11.3 \pm 8.0$ years (range, 4 months to 44 years). In the scope of study, the items used for developing the measurement tools are presented in Table 1 in terms of extremity (only lower, only upper).

\section{Exploratory factor analysis results}

In the first stage, the EFA was applied to evaluate the internal construct validity of the measurement tool consisting of 32 items. As a result, the RMSEA value for the two-factor model was 0.078 and this value is very close to the acceptable limit of 0.08 for adequate fit. Considering the factor loadings and clinical classifications of the items, the first dimension was named as "self-care-mobility-household activities related to lower extremity" and the second dimension was named as "self-care-mobility-household activities related to upper extremity" (Table 2).

When Table 2 was examined, although the h2, h15, and h17 items were loaded with a factor loading of more than 0.40 in both dimensions, they were evaluated in the factor with higher factor loading. This evaluation is consistent with the clinical classification. Although h13 item also loaded with salient loadings on both dimensions, the group with a higher factor loading was incompatible with the clinical classification. When the content of this item was examined in detail, it was concluded that patients may have responded by considering the effect of lower extremity in the process of grasping and lowering the object. Therefore, also considering the opinion of the clinician, h13 was associated with the upper extremity.

According to the results of EFA, the factor loadings of the items in the "self-care-mobility-household activities related to the lower extremity" factor were between 0.444 and 0.937 , while the factor loadings of the items in the "self-care-mobility-house household 


\begin{tabular}{|c|c|c|c|}
\hline & $\begin{array}{c}\text { TABLE } 1 \\
\text { Distribution of items by extremities }\end{array}$ & & \\
\hline Abbreviation & Item & Original scale section & Extremity \\
\hline WD2.1 & $\begin{array}{l}\text { In the past } 30 \text { days, how much difficulty did you have in standing for } \\
\text { long periods such as } 30 \text { minutes? }\end{array}$ & Getting around & Lower \\
\hline WD2.2 & $\begin{array}{l}\text { In the past } 30 \text { days, how much difficulty did you have in standing up } \\
\text { from sitting down? }\end{array}$ & Getting around & Lower \\
\hline WD2.3 & $\begin{array}{l}\text { In the past } 30 \text { days, how much difficulty did you have in moving around } \\
\text { inside your home? }\end{array}$ & Getting around & Lower \\
\hline WD2.4 & $\begin{array}{l}\text { In the past } 30 \text { days, how much difficulty did you have in getting out of } \\
\text { your home? }\end{array}$ & Getting around & Lower \\
\hline WD2.5 & $\begin{array}{l}\text { In the past } 30 \text { days, how much difficulty did you have in walking a long } \\
\text { distance such as a kilometer [or equivalent]? }\end{array}$ & Getting around & Lower \\
\hline WD3.3 & In the past 30 days, how much difficulty did you have in eating? & Self-care & Upper \\
\hline WD4.5 & In the past 30 days, how much difficulty did you have in sexual activities? & Getting along with people & Lower \\
\hline A11 & During the past month, could you easily write with a pen or pencil? & Hand and finger function & Upper \\
\hline A 12 & During the past month, could you easily button a shirt or blouse? & Hand and finger function & Upper \\
\hline A13 & During the past month, could you easily turn a key in a lock? & Hand and finger function & Upper \\
\hline $\mathrm{A} 14$ & During the past month, could you easily tie a knot or a bow? & Hand and finger function & Upper \\
\hline A15 & During the past month, could you easily open a new jar of food? & Hand and finger function & Upper \\
\hline N10 & I can walk about only indoors & Physical abilities & Lower \\
\hline N11 & I find it hard to bend & Physical abilities & Lower \\
\hline N14 & I'm unable to walk at all & Physical abilities & Lower \\
\hline N17 & I have trouble getting up and down stairs and steps & Physical abilities & Lower \\
\hline $\mathrm{N} 27$ & I find it hard to stand for long (e.g., at the kitchen sink, waiting in a line) & Physical abilities & Lower \\
\hline N35 & $\begin{array}{l}\text { I need help to walk about outside (e.g., a walking aid or someone to } \\
\text { support me) }\end{array}$ & Physical abilities & Lower \\
\hline $\mathrm{H} 2$ & Over the past week, are you able to shampoo your hair? & Dressing \& grooming & Upper \\
\hline $\mathrm{H} 3$ & Over the past week, are you able to stand up from a straight chair? & Arising & Lower \\
\hline $\mathrm{H} 4$ & Over the past week, are you able to get in and out of bed? & Arising & Lower \\
\hline H5 & Over the past week, are you able to cut your meat? & Eating & Upper \\
\hline H6 & Over the past week, are you able to lift a full cup or glass to your mouth? & Eating & Upper \\
\hline $\mathrm{H} 7$ & Over the past week, are you able to open a new milk carton? & Eating & Upper \\
\hline $\mathrm{H} 8$ & Over the past week, are you able to walk outdoors on flat ground? & Walking & Lower \\
\hline H9 & Over the past week, are you able to climb up five steps? & Walking & Lower \\
\hline $\mathrm{H} 12$ & Over the past week, are you able to get on and off the toilet? & Hygiene & Lower \\
\hline $\mathrm{H} 13$ & $\begin{array}{l}\text { Over the past week, are you able to reach and get down a 5-pound object } \\
\text { (such as a bag of sugar) from just above your head? }\end{array}$ & Reach & Upper \\
\hline H15 & Over the past week, are you able to open car doors? & Grip & Upper \\
\hline H16 & $\begin{array}{l}\text { Over the past week, are you able to open jars which have been previously } \\
\text { opened? }\end{array}$ & Grip & Upper \\
\hline $\mathrm{H} 17$ & Over the past week, are you able to turn faucets on and off? & Grip & Upper \\
\hline H19 & Over the past week, are you able to get in and out of a car? & Activities & Lower \\
\hline
\end{tabular}




\begin{tabular}{|c|c|c|c|c|c|c|c|}
\hline \multicolumn{8}{|c|}{$\begin{array}{c}\text { TABLE } 2 \\
\text { Results of exploratory factor analysis (EFA) }\end{array}$} \\
\hline Abbreviation & $\mathrm{F} 1$ & $\mathrm{~F} 2$ & Extremity & Abbreviation & F1 & $\mathrm{F} 2$ & Extremity \\
\hline WD2.1 & 0.895 & -0.149 & Lower & $\mathrm{N} 27$ & 0.937 & -0.329 & Lower \\
\hline WD2.2 & 0.772 & -0.014 & Lower & N35 & 0.909 & 0.019 & Lower \\
\hline WD2.3 & 0.853 & -0.033 & Lower & $\mathrm{H} 2$ & 0.446 & 0.561 & Upper \\
\hline WD2.4 & 0.881 & -0.056 & Lower & H3 & 0.912 & 0.100 & Lower \\
\hline WD2.5 & 0.848 & -0.069 & Lower & $\mathrm{H} 4$ & 0.915 & 0.085 & Lower \\
\hline WD3.3 & 0.369 & 0.533 & Upper & H5 & 0.368 & 0.641 & Upper \\
\hline WD4.5 & 0.549 & 0.100 & Lower & H6 & 0.306 & 0.655 & Upper \\
\hline AIMS11 & -0.004 & 0.911 & Upper & $\mathrm{H} 7$ & 0.366 & 0.627 & Upper \\
\hline AIMS12 & -0.026 & 0.960 & Upper & $\mathrm{H} 8$ & 0.925 & 0.007 & Lower \\
\hline AIMS13 & 0.044 & 0.907 & Upper & H9 & 0.801 & 0.151 & Lower \\
\hline AIMS14 & -0.085 & 0.996 & Upper & H12 & 0.658 & 0.243 & Lower \\
\hline AIMS15 & 0.141 & 0.718 & Upper & H13 & 0.532 & 0.454 & Upper \\
\hline N10 & 0.813 & 0.019 & Lower & H15 & 0.503 & 0.543 & Upper \\
\hline N11 & 0.759 & 0.006 & Lower & H16 & 0.381 & 0.603 & Upper \\
\hline N14 & 0.568 & 0.124 & Lower & H17 & 0.444 & 0.542 & Upper \\
\hline N17 & 0.907 & -0.170 & Lower & H19 & 0.613 & 0.344 & Lower \\
\hline
\end{tabular}

\begin{tabular}{|c|c|c|c|c|c|c|c|c|c|c|c|}
\hline & & & & esults o & confirm & acto & inalysis (CFA & & & & \\
\hline & Abbreviation & F.L. & SE & F.L./SE & $p$ & & Abbreviation & F.L. & SE & F.L./SE & $p$ \\
\hline & WD2.1 & 0.779 & 0.028 & 28.23 & $<0.001$ & & H12 & 0.847 & 0.026 & 32.33 & $<0.001$ \\
\hline 音 & WD2.2 & 0.753 & 0.031 & 24.34 & $<0.001$ & 気 & H19 & 0.910 & 0.023 & 40.35 & $<0.001$ \\
\hline 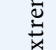 & WD2.3 & 0.816 & 0.027 & 30.64 & $<0.001$ & 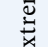 & WD3.3 & 0.814 & 0.035 & 23.11 & $<0.001$ \\
\hline "艹 & WD2.4 & 0.839 & 0.023 & 36.16 & $<0.001$ & ڤ̆ & A11 & 0.877 & 0.018 & 47.45 & $<0.001$ \\
\hline 욜 & WD2.5 & 0.795 & 0.027 & 29.74 & $<0.001$ & 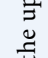 & A12 & 0.914 & 0.015 & 60.95 & $<0.001$ \\
\hline$\stackrel{9}{0}$ & WD4.5 & 0.624 & 0.052 & 11.95 & $<0.001$ & $\stackrel{0}{T}$ & A13 & 0.909 & 0.016 & 55.63 & $<0.001$ \\
\hline 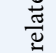 & N10 & 0.820 & 0.039 & 20.91 & $<0.001$ & $\frac{\pi}{2}$ & A14 & 0.891 & 0.014 & 63.36 & $<0.001$ \\
\hline$\stackrel{\mathscr{Q}}{:}$ & N11 & 0.759 & 0.040 & 18.89 & $<0.001$ & $\stackrel{\mathscr{Z}}{=}$ & A15 & 0.774 & 0.027 & 29.02 & $<0.001$ \\
\hline 売 & N14 & 0.661 & 0.090 & 7.35 & $<0.001$ & $\stackrel{Z}{Z}$ & $\mathrm{H} 2$ & 0.906 & 0.016 & 57.03 & $<0.001$ \\
\hline$\frac{1}{8}$ & N17 & 0.775 & 0.041 & 18.81 & $<0.001$ & 긍 & H5 & 0.907 & 0.016 & 57.29 & $<0.001$ \\
\hline$\tilde{\Xi}$ & N27 & 0.707 & 0.044 & 16.10 & $<0.001$ & $\stackrel{0}{0}$ & H6 & 0.866 & 0.022 & 39.01 & $<0.001$ \\
\hline 佘 & N35 & 0.913 & 0.021 & 43.13 & $<0.001$ & $\stackrel{3}{=}$ & H7 & 0.892 & 0.017 & 51.96 & $<0.001$ \\
\hline छ & H3 & 0.979 & 0.009 & 108.24 & $<0.001$ & छ & H13 & 0.893 & 0.017 & 53.07 & $<0.001$ \\
\hline పె & $\mathrm{H} 4$ & 0.966 & 0.010 & 99.25 & $<0.001$ & تँ & H15 & 0.952 & 0.015 & 62.98 & $<0.001$ \\
\hline 岕 & H8 & 0.917 & 0.017 & 54.89 & $<0.001$ & ह & H16 & 0.884 & 0.018 & 48.29 & $<0.001$ \\
\hline & H9 & 0.911 & 0.018 & 51.78 & $<0.001$ & & H17 & 0.888 & 0.019 & 45.74 & $<0.001$ \\
\hline
\end{tabular}




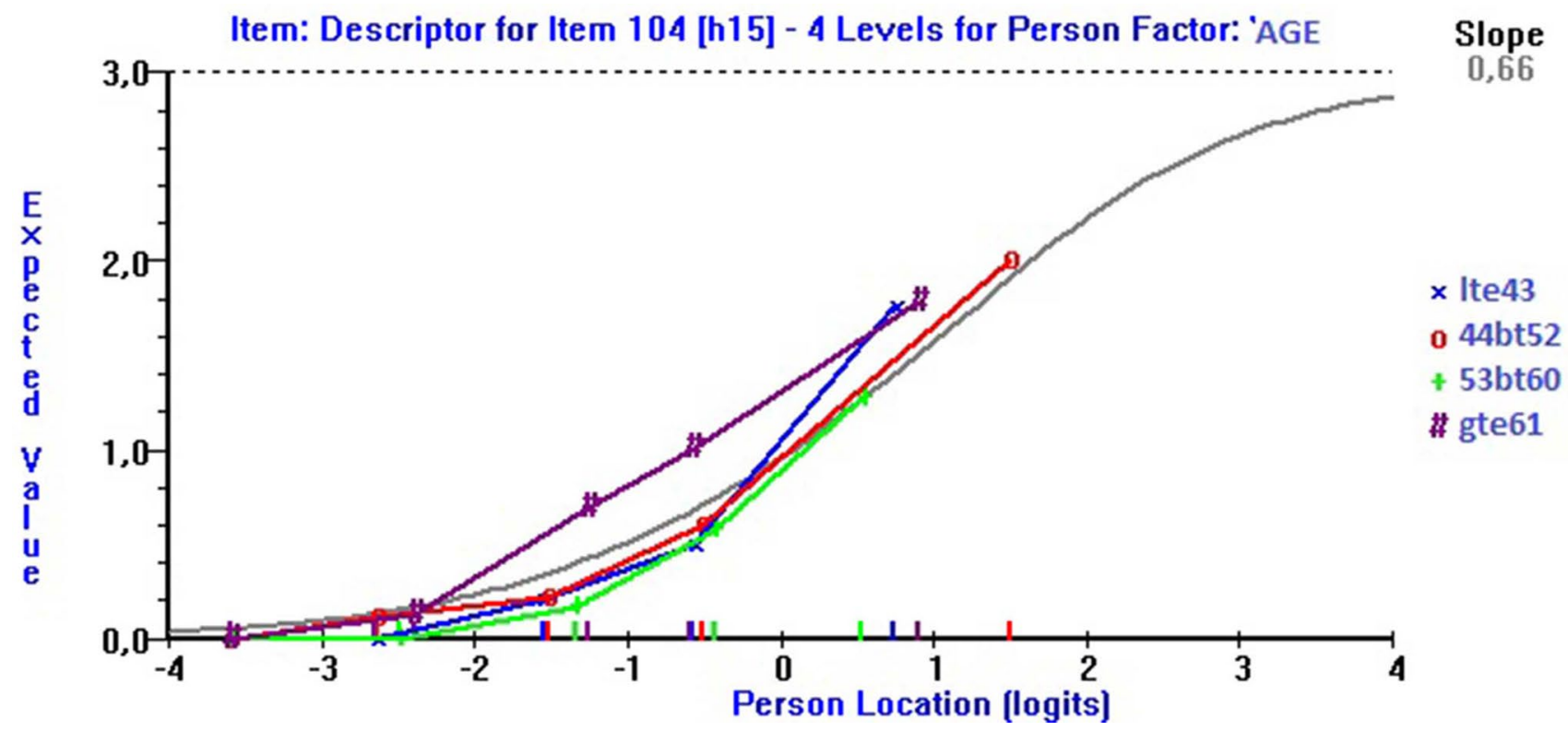

Figure 1. Item characteristic curves of the item "h15-open car doors?" according to age groups.

activities related to the upper extremity" factor were between 0.454 and 0.996 .

\section{Confirmatory factor analysis results}

The CFA was applied to determine whether the upper and lower extremity factors in the Table 1 (separately) were actually composed of relevant items. As a result of the CFA, the RMSEA value was 0.085 , the CFI value was 0.958 and the TLI value was 0.954 . As the first value was close to 0.08 and the other values were greater than 0.90 , the results obtained from CFA were evaluated as satisfactory. When the factor loadings of the items were examined according to the factors, all items had a factor loading of $\geq 0.40$ in the relevant dimensions (Table 3).

\section{Rasch analysis results}

At this stage, the internal construct validity of the measurement tool was investigated with a total of 32 items by ignoring the clinical structure given in Table 1 and by the PCM under Rasch analysis. After combining the categories of items with disordered thresholds, unidimensionality was examined as the first step. It was observed that the structure of unidimensionality was not provided. Thus, the similarity of the dimensions obtained from the positive and negative loaded items on the first principal component was compared with the clinical structure. The 14 items identified within the clinical structure for the upper extremity corresponded to the item set positively loaded in the 32-item Rasch analysis. Of the 18 items identified in the clinical structure for the lower extremity, 16 of the 32 items in the Rasch analysis corresponded to a set of items that were negatively loaded. As a result of Rasch analysis, the remaining two items were not loaded to any group.

Rasch analysis of the measurement tool "self-Care-mobility-household activities related to the upper extremity"

After combining the categories of items with disordered thresholds, the model fit of the 14 items were examined. Following this, the unidimensionality of the measurement tool was tested. As items A14, H7 and $\mathrm{H} 13$ violated the unidimensionality assumption, those items were removed. Local independence assumption was also hold. When DIF was evaluated both graphically and statistically, only the item "h15- Open car doors?" showed uniform DIF according to the age group (Figure 1).

As shown in Figure 1, opening car doors was found to be more difficult for patients over 61 years old. As this item was considered necessary to question the level of functionality related to the patient's self-care, it was kept in the measurement tool.

There was no item showing misfit, as assessed by the Bonferroni correction (Table 4). Since the residual values were between \pm 2.5 and the chi-square $\left(\chi^{2}\right)$ values are higher than the value of $p$ value 


\begin{tabular}{|lccccc|}
\multicolumn{5}{c}{ TABLE 4 } \\
\multicolumn{5}{c}{$\begin{array}{c}\text { Item fit statistics of "self-care-mobility-household activities related } \\
\text { to the upper extremity" }\end{array}$} \\
\hline Abbreviation & Beta & SE & Residual & Chi-square & $p$ \\
\hline WD3.3 & 1.390 & 0.137 & 1.665 & 13.303 & 0.010 \\
A11 & -0.520 & 0.124 & -0.315 & 5.210 & 0.266 \\
A12 & -0.139 & 0.129 & -1.161 & 4.824 & 0.306 \\
A13 & -0.327 & 0.125 & -1.053 & 4.364 & 0.359 \\
A15 & -2.050 & 0.125 & 1.914 & 10.257 & 0.036 \\
H2 & -0.306 & 0.107 & 0.105 & 1.042 & 0.903 \\
H5 & -0.393 & 0.106 & -1.303 & 5.157 & 0.272 \\
H6 & 1.163 & 0.130 & -1.780 & 3.870 & 0.424 \\
H15 & 0.795 & 0.125 & -2.199 & 6.670 & 0.154 \\
H16 & -0.374 & 0.104 & 0.046 & 2.941 & 0.568 \\
H17 & 0.762 & 0.122 & -1.730 & 4.281 & 0.369 \\
\hline SE: Standard error; WD: Whodas-II; A: AIMS2; H: HAQ. & & & \\
\hline
\end{tabular}

with Bonferroni correction $(0.05 / 11=0.005)$, all items in the measurement tool fitted to the model (Table 4). Overall mean item fit residual was -0.528 logit (SD 1.365) and mean person fit residual was -0.412 logit (SD 1.160). Item-trait interaction was non-significant, supporting the invariance of items $\left(\chi^{2}: 61.92, \mathrm{p}=0.039\right)$.

Rasch analysis of the measurement tool

"self-care-mobility-household activities

related to the lower extremity"

After combining the categories of items with disordered thresholds, the model fit of the 16 items were examined. As the items WD2.1, WD4.5, H3, $\mathrm{H} 8$, and N35 showed misfit to the model, these items were removed. When the unidimensionality, local independence assumptions and existence of DIF were evaluated, both assumptions were hold and there were no items showing DIF.

There was no item showing misfit, as assessed by the Bonferroni correction (Table 5). Since the residual values are between \pm 2.5 and $\chi^{2}$ values are higher than the value of $\mathrm{p}$ value with Bonferroni correction $(0.05 / 11=0.005)$, all items in the measurement tool fitted to the model (Table 5). Overall mean item fit

\section{TABLE 5}

Item fit statistics of "self-care-mobility-household activities related to the lower extremity" measurement tool

\begin{tabular}{|lccccc|}
\hline Abbreviation & Beta & SE & Residual & Chi-square & $p$ \\
\hline WD2.2 & 0.919 & 0.117 & 0.344 & 4.447 & 0.349 \\
WD2.3 & 1.655 & 0.124 & -2.306 & 7.253 & 0.123 \\
WD2.4 & 0.024 & 0.080 & -0.462 & 6.155 & 0.188 \\
WD2.5 & -1.908 & 0.112 & 0.356 & 0.539 & 0.970 \\
N10 & 0.984 & 0.185 & -0.608 & 6.239 & 0.182 \\
N11 & -1.061 & 0.154 & 0.149 & 3.758 & 0.440 \\
N17 & -2.350 & 0.163 & 0.555 & 7.623 & 0.106 \\
N27 & -3.703 & 0.199 & 0.200 & 1.035 & 0.904 \\
H4 & 2.541 & 0.137 & -2.139 & 7.761 & 0.101 \\
H9 & 1.412 & 0.114 & -0.496 & 3.791 & 0.435 \\
H12 & 1.486 & 0.117 & 0.857 & 5.971 & 0.201 \\
\hline SE: Standard error; WD: Whodas-II; A: AIMS2; H: HAQ. & & & \\
\hline
\end{tabular}


residual was -0.323 logit (SD 1.045) and mean person fit residual was $-0.305 \operatorname{logit}$ (SD 0.768). Item-trait interaction was non-significant, supporting the invariance of items $\left(\chi^{2}: 54.57, \mathrm{p}=0.132\right)$.

When a comparison was made between the "self-care-mobility-household activities related to the lower extremity" measurement tools obtained by the clinical structure and factor analysis and obtained by the Rasch analysis, 11 items were common. With the exception of two additional items (WD4.5 and H19), there was no significant difference between the psychometric properties of the measurement tools. Therefore, when clinicians decide between these two measurement tools for examining the "self-caremobility-household activities related to the lower extremity", it would be appropriate for taking into account the contribution of WD4.5 and H19.

\section{DISCUSSION}

In evaluating the internal construct validity, which is probably the most important type of validity in scale development, EFA and CFA from the factor analytic approaches and Rasch analysis from modern approaches are among the most widely used methods.

Within the scope of this study, two measurement tools that evaluate the functional levels for lower and upper extremities separately in patients with RA in terms of "self-care-mobility-household activities" were developed. Internal construct validity of the tools was evaluated by both factor analysis (EFA and CFA) and Rasch analysis. When the total 32 items were evaluated by EFA, the model fit of the two-factor structure was adequate. Except for one item, all items were loaded on the factors in accordance with the clinical structure. In the second stage, CFA was applied to determine whether the upper and lower extremity structures identified as clinically were actually composed of related items. Considering the GoF statistics, satisfactory results were achieved.

Based on the Rasch analysis, items that did not fit to the model showed DIF and violated the unidimensionality assumption were excluded from the measurement tool. While choosing between these two measurement tools developed for lower extremity, it is appropriate for clinicians to consider the contribution of the items that question sexual life and the activity of getting in and out of the car in the light of additional information.
The discrepancy in the results of factor analysis and Rasch analysis is an expected situation considering the differences in the process of the methods. Review of the literature reveals that some of the studies carried out in the field of scale development are evaluated only with factor analysis/Rasch analysis and some others with both methods. ${ }^{[19,20]}$ The common factor analysis (EFA and CFA) creates independent, conceptually significant factors that represent the related structure from dependent items. With this structure, factor analysis is a multivariate analysis method that is basically performed with the aim of data reduction. In view of the modern test theory, Rasch analysis evaluates whether there are any items showing disordered thresholds, misfit, and DIF in addition to the dimensionality of the items in the measurement tool. In the light of this information, when the factor analysis and Rasch analysis are compared, Rasch analysis can be said to have a structure that includes factor analysis. However, according to the literature review in the fields of "psychometry" and "measurement and evaluation", factor analytic approaches were frequently used in the years, when classical test theory was developed and, in parallel with the developments in technology, modern test theories have emerged and methods such as Rasch analysis have become increasingly more popular.

In conclusion, from these two methods that have similarities in terms of their functioning, factor analysis methods can be applied to the evaluation of prior unidimensionality before unidimensionality examination to be performed within the scope of the Rasch analysis. As a different field of use, the measurement tools revealing the internal construct validity as a result of the Rasch analysis can be verified by the CFAs to be performed on different data sets. Based on these findings, we consider that the reliability of the results obtained from the use of these two complementary approaches is more important than the application of factor analysis or Rasch analysis methods alone, in the examination of the newly developed scales in the field of health or the validity of internal construct of the existing scales to be adapted for different languages/cultures/groups.

\section{Declaration of conflicting interests}

The authors declared no conflicts of interest with respect to the authorship and/or publication of this article.

Funding

The authors received no financial support for the research and/or authorship of this article. 


\section{REFERENCES}

1. World Health Organization. International classification of functioning, disability and health (ICF). Geneva: World Health Organization; 2001.

2. Kilic L, Erden A, Bingham CO 3rd, Gossec L, Kalyoncu U. The Reporting of patient-reported outcomes in studies of patients with rheumatoid arthritis: A systematic review of 250 articles. J Rheumatol 2016;43:1300-5.

3. Fries JF, Spitz P, Kraines RG, Holman HR. Measurement of patient outcome in arthritis. Arthritis Rheum 1980;23:137-45.

4. Orbai AM, Bingham CO 3rd. Patient reported outcomes in rheumatoid arthritis clinical trials. Curr Rheumatol Rep 2015;17:28

5. Tabachnick BG, Fidell LS. Principal components and factor analysis. In: Tabachnick BG, Fidell LS, editors. Using Multivariate Statistics. 5th ed. Boston: Pearson Education, Inc.; 2007. p. 607-75.

6. Rasch G. Probabilistic models for some intelligence and attainment tests. Chicago: University of Chicago Press; 1960.

7. Kaskatı OT. Rasch modelleri kullanarak romatoid artirit hastaları özürlülük değerlendirimi için bilgisayar uyarlamalı test yönteminin geliştirilmesi. Ankara: Ankara Üniv.; 2011.

8. World Health Organization (WHO), WHODAS II Disability Assessment Schedule Training Manual: A guide to administration [Internet], Geneve: WHO; 2004.

9. Hunt SM, McEwen J, McKenna SP. Measuring health status: A new tool for clinicians and epidemiologists. J R Coll Gen Pract 1985;35:185-8.

10. Meenan RF, Mason JH, Anderson JJ, Guccione AA, Kazis LE. AIMS2. The content and properties of a revised and expanded arthritis impact measurement scales health status questionnaire. Arthritis Rheum 1992;35:1-10.

11. Kutlay S, Küçükdeveci AA, Elhan AH, Oztuna D, Koç N, Tennant A. Validation of the World Health Organization Disability Assessment Schedule II
(WHODAS-II) in patients with osteoarthritis. Rheumatol Int 2011;31:339-46.

12. Kücükdeveci AA, McKenna SP, Kutlay S, Gürsel Y, Whalley $\mathrm{D}$, Arasil T. The development and psychometric assessment of the Turkish version of the Nottingham Health Profile. Int J Rehabil Res 2000;23:31-8.

13. Küçükdeveci AA, Sahin H, Ataman S, Griffiths B, Tennant A. Issues in cross-cultural validity: Example from the adaptation, reliability, and validity testing of a Turkish version of the Stanford health assessment questionnaire. Arthritis Rheum 2004;51:14-9.

14. Atamaz F, Hepguler S, Oncu J. Translation and validation of the Turkish version of the arthritis impact measurement scales 2 in patients with knee osteoarthritis. J Rheumatol 2005;32:1331-6.

15. Öztuna D. Kas-iskelet sistemi sorunlarının özürlülük değerlendiriminde bilgisayar uyarlamalı test yönteminin uygulanmasi. [Uzmanlık Tezi] Ankara: Ankara Üniversitesi / Sağlık Bilimleri Enstitüsü / Biyoistatistik Anabilim Dalı; 2008.

16. Muthen, Muthen. MPlus, Version 6, Los Angeles, CA; 2006.

17. Doğanay Erdoğan B. Çoklu atama yöntemlerinin rasch modelleri için performansının benzetim çalışması ile incelenmesi. [Uzmanlık Tezi] Ankara: Ankara Üniversitesi / Sağlık Bilimleri Enstitüsü / Biyoistatistik Anabilim Dali; 2012.

18. Andrich D, Lyne A, Sheridan B, Luo G. RUMM2020. Rasch Unidimensional Measurement Models Software. RUMM Laboratory, Perth; 2003.

19. Chachamovich E, Fleck MP, Trentini CM, Laidlaw K, Power MJ. Development and validation of the Brazilian version of the Attitudes to Aging Questionnaire (AAQ): An example of merging classical psychometric theory and the Rasch measurement model. Health Qual Life Outcomes 2008;6:5.

20. Allison C, Baron-Cohen S, Wheelwright SJ, Stone MH, Muncer SJ. Psychometric analysis of the Empathy Quotient (EQ). Personality and Individual Differences 2011;51:829-35. 